\title{
Health Resources in the Western Economic Zone of the Republic of Sakha (Yakutia) and Their Relationship with Indicators of Population Health
}

\author{
Leonid F. Timofeev ${ }^{1, *}$, Palmira G. Petrova ${ }^{1}$, Natalia V. Borisova ${ }^{1}$, Lena K. \\ Turkebaeva $^{1}$ and Artem L.Timofeev ${ }^{1}$ \\ ${ }^{I}$ North-Eastern Federal University, Institute of Medicine ,27, Oyunskogo str., Yakutsk, 677016, Russia \\ ${ }^{*}$ Corresponding author.Email: If.timofeev@s-vfu.ru
}

\begin{abstract}
S
To achieve the proper level of accessibility and quality of medical care to the population, the provision of the municipalities of the republic with the necessary resources (material, technical, financial, human, information, etc.) is of no small importance. In this work, we analyzed the resource provision in the districts (uluses) of the Western Economic Zone (WEZ) according to the indicators included in the official statistical reporting: the availability of medical personnel (doctors, nurses), round-the-clock hospital beds (all - per 10,000 population) and the capacity of outpatient clinics institutions (OCI, in shift visits). An analysis is made of the relationship of a number of indicators characterizing public health with the resource provision of districts (uluses), by correlation coefficients calculated for the period 2007-016.
\end{abstract}

Keywords: medical care, health resources, western economic zone, Republic of Sakha, Yakutia, population health

\section{INTRODUCTION}

Issues of protecting public health and the development of healthcare have always been among the priorities in the activities of state bodies of Yakutia. So, in the Strategy of socio-economic development of the Republic of Sakha (Yakutia) (RS (Y)) until 2030 with the definition of the main directions until 2050 there are sections directly or indirectly affecting the health sector: demographic and family policy, innovative health development, physical education and sports, social protection of the population. In the section "Development of territorial planning", the entire territory of the republic is divided into 5 economic zones: Arctic, Western, Central, Eastern and Southern [1].

Subsequently, this Strategy underwent some changes and was approved by the Law of the Republic of Sakha (Yakutia) [2]. Since the indicator values of the expected results are planned by 2032 , there is a need to assess certain characteristics of public health at the current stage, including taking into account their relationship with the resources for health care. This article will analyze the availability of resources in the Western Economic Zone.

It is noteworthy that 6 districts of the WEZ (Verkhnevilyuysky, Vilyui, Lensky, Mirninsky, Nyurbinsky and Suntarsky) are included in the so-called "diamond province", of which Mirny and Nyurbinsky districts are the territories where the bulk of diamonds are mined in the Russian Federation.

\section{METHODS AND MATERIALS}

The materials used are the official statistics of the republic (Sakha (Yakutia) stat) and the Ministry of Health (YRMIAC) [3-5]. To analyze these indicators, the percentile (centile) method was used, which is widely used and used by us in developing the criteria for regionalization of the North of the Russian Federation 
and in preparing a number of articles. According to this method, areas with indicators up to the 10th percentile belonged to areas with a low level of resource provision, from 10 to the 25 th percentile - below the average, from 75 to the 90th - above the average and above the 90th percentile - with a high level. Obviously, with indicators ranging from the 25 th to the 75 th percentile, the districts belonged to the group with average values of resource provision.

Table 1. Provision of medical personnel in the areas of the Western Economic Zone in 1990, 1995, 2000,2005 and 2010-2016 (per 10,000 us.)

\begin{tabular}{|c|c|c|c|c|c|c|c|c|c|c|c|}
\hline Districts & 1990 & 1995 & $2000^{*}$ & 2005 & 2010 & 2011 & 2012 & 2013 & 2014 & 2015 & 2016 \\
\hline \multicolumn{12}{|c|}{ Provision of doctors } \\
\hline Verkhnevilyuysky & 26 & 25 & 25 & 26 & 31.5 & 28.6 & 30.8 & 29.2 & 28.2 & 28.2 & 31.5 \\
\hline Vilyui & 38 & 32 & 36 & 36 & 37.7 & 35.7 & 33.8 & 30.1 & 27.6 & 27.0 & 30.0 \\
\hline Lensky & 22 & 14 & 25 & 26 & 26.9 & 28.0 & 25.1 & 26.5 & 24.2 & 25.8 & 25.9 \\
\hline Mirny & 29 & 32 & 33 & 29 & 30.4 & 29.7 & 30.4 & 30.9 & 32.7 & 33.1 & 32.2 \\
\hline Nyurba & 31 & 28 & 27 & 32 & 37.7 & 34.1 & 34.8 & 33.9 & 34.0 & 34.2 & 32.7 \\
\hline Olekminsky & 25 & 20 & 21 & 26 & 27.0 & 22.8 & 22.3 & 23.0 & 21.6 & 20.5 & 19.1 \\
\hline Suntar & 38 & 27 & 28 & 27 & 31.2 & 31.5 & 34.9 & 31.6 & 32.2 & 31.1 & 32.5 \\
\hline In the $R S(Y)$ & 42 & 44 & 46 & 50 & 52.6 & 48.3 & 47.7 & 47.9 & 48.5 & 48.1 & 48.4 \\
\hline \multicolumn{12}{|c|}{ Provision of nursing staff } \\
\hline Verkhnevilyuysky & 115 & 117 & 105 & 114 & 104.8 & 104.4 & 107.9 & 113.5 & 108.5 & 111.6 & 108.4 \\
\hline Vilyui & 143 & 132 & 136 & 136 & 119.5 & 114.6 & 97.6 & 97.3 & 114.0 & 108.2 & 108.8 \\
\hline Lensky & 76 & 74 & 77 & 78 & 64.7 & 61.0 & 63.3 & 64.0 & 64.3 & 65.1 & 66.9 \\
\hline Mirny & 78 & 91 & 88 & 80 & 74.4 & 76.6 & 79.3 & 76.8 & 77.5 & 75.6 & 74.2 \\
\hline Nyurba & 119 & 108 & 118 & 132 & 126.2 & 118.4 & 122.3 & 119.5 & 118.1 & 116.1 & 117.7 \\
\hline Olekminsky & 94 & 103 & 103 & 127 & 113.6 & 104.3 & 100.8 & 100.2 & 91.1 & 85.2 & 89.5 \\
\hline Suntar & 132 & 128 & 118 & 130 & 119.0 & 118.7 & 118.2 & 118.8 & 119.7 & 116.1 & 116.8 \\
\hline In the RS $(Y)$ & 118 & 130 & 133 & 136 & 121.5 & 117.3 & 116.0 & 115.1 & 113.3 & 112.7 & 111.7 \\
\hline
\end{tabular}

\section{RESULTS AND DISCUSSION}

Resource security. According to the results of 2016, the average republican indicator of the provision of medical personnel is 48.4 per 10,000 population (Table 1). Of the 7 districts under consideration included in the Western Economic Zone (WEZ), the worst situation is in Olekminsky, Lensky (19.1 and 25.9, respectively the level is low on a national scale), Vilyuisky (30.0) and Verkhnevilyuysky (31.5) areas (levels below average). Throughout the period since 1990, a shortage of medical personnel was also noted in these areas. And for a number of years - in Mirny and Suntar districts.

In 2016, the provision with average medical workers was higher than the national average (111.7 per 10,000 population), Nyurba (117.7 per 10,000 population) and

Suntar (116.8) uluses, and this is only average levels of security. In Lensky (66.9), Mirny (74.2) and Olekminsky (89.5) districts, the indicators were below the national average, and were within the provision of low (2 districts) and below the average. During the period under review, unsatisfactory security is also observed in these areas.
Consider the security data of municipalities of the WEZ around the clock hospital beds (table. 2). The average republican indicator for 2016 was 92.0 per 10,000 population, and the indicator of the Verkhnevilyuysky ulus alone exceeds this level (104.1 per 10,000 population, the level is above average). At the same time, in the Vilyui (61.2), Lensky (73.0) districts, indicators on a national scale are low and below average, respectively. During the period under review, insufficient security was noted, in addition to the mentioned areas, also in the Suntar ulus.

As for the provision of outpatient facilities in shift visits (OCI, visits per shift), This indicator on average in the RS (Y) reached 267.0 in 2016 (Table 3). In the Lensky district, the OCI coverage indicator turned out to be the worst (183.2 pos./cm.). In addition, we see insufficient OCI capacity in the Verkhnevilyuysky (261.6) and Vilyui (241.5) uluses (levels below average). It should be noted that years with insufficient OCI power were observed in these uluses over almost the entire period under consideration. In other areas, average values prevailed, however, in the Mirny, 
Olekminsky and Suntarsky districts, certain years with insufficient OCI power were noted.

Table 2. Provision of round-the-clock hospital beds in areas of the Western Economic Zone in 1990, 1995, 2000,

2005 and 2010-2016 (per 10,000 population)

\begin{tabular}{|l|l|l|l|l|l|l|l|l|l|l|l|}
\hline Districts & 1990 & 1995 & 2000 & $2005^{*}$ & 2010 & 2011 & 2012 & 2013 & 2014 & 2015 & 2016 \\
\hline Verkhnevilyuysky & 161.0 & 171.3 & 158.4 & 152 & 112.8 & 110.9 & 113.6 & 115.0 & 114.7 & 109.2 & 104.1 \\
\hline Vilyui & 181.0 & 194.5 & 146.4 & 147 & 90.5 & 90.4 & 91.9 & 92.8 & 92.5 & 75.9 & 61.2 \\
\hline Lensky & 110.0 & 110.9 & 100.9 & 123 & 92.4 & 85.7 & 83.6 & 84.3 & 85.4 & 79.2 & 73.0 \\
\hline Mirny & 99.0 & 100.6 & 98.6 & 105 & 93.9 & 97.6 & 101.6 & 102.8 & 102.9 & 93.7 & 86.5 \\
\hline Nyurba & 166.0 & 139.5 & 122.7 & 141 & 108.6 & 94.7 & 105.3 & 106.1 & 106.6 & 97.2 & 92.4 \\
\hline Olekminsky & 153.0 & 111.8 & 110.4 & 135 & 112.8 & 104.7 & 98.1 & 99.4 & 100.1 & 84.8 & 73.6 \\
\hline Suntar & 187.0 & 145.9 & 134.0 & 121 & 91.3 & 90.0 & 92.8 & 93.0 & 93.8 & 79.5 & 76.8 \\
\hline In the RS $(Y)$ & 156.0 & 150.4 & 142.0 & 153 & 109.8 & 107.5 & 106.8 & 106.9 & 106.4 & 98.1 & 92.0 \\
\hline
\end{tabular}

Table 3. Provision of outpatient facilities in the areas of the Western Economic Zone in 1990, 2000, 2005 and 2010 2016 (power in visits per shift)

\begin{tabular}{|l|l|l|l|l|l|l|l|l|l|l|}
\hline Districts & $1990^{*}$ & $2000^{*}$ & $2005^{*}$ & 2010 & 2011 & 2012 & 2013 & 2014 & 2015 & 2016 \\
\hline Verkhnevilyuysky & 221 & 251 & 257 & 257.1 & 253.7 & 257.5 & 260.4 & 261.8 & 261.7 & 261.6 \\
\hline Vilyui & 157 & 196 & 235 & 238.6 & 238.5 & 242.0 & 243.3 & 244.1 & 243.2 & 241.5 \\
\hline Lensky & 129 & 173 & 180 & 173.5 & 168.2 & 170.6 & 177.5 & 179.9 & 181.8 & 183.2 \\
\hline Mirny & 108 & 266 & 234 & 254.4 & 261.2 & 275.9 & 279.7 & 282.0 & 280.0 & 276.0 \\
\hline Nyurba & 213 & 267 & 279 & 294.4 & 278.0 & 357.7 & 360.9 & 363.2 & 365.0 & 366.8 \\
\hline Olekminsky & 197 & 226 & 245 & 273.9 & 253.6 & 260.1 & 263.4 & 266.1 & 267.7 & 269.4 \\
\hline Suntar & 100 & 271 & 271 & 276.2 & 272.0 & 278.1 & 281.6 & 284.4 & 286.2 & 287.3 \\
\hline In the RS (Y) & 214 & 272 & 274 & 258.6 & 255.8 & 258.2 & 259.7 & 260.2 & 260.6 & 267.0 \\
\hline
\end{tabular}

Legend:

\begin{tabular}{|c|c|}
\hline 29.0 & low security \\
\hline 31.5 & level below average \\
\hline 43.2 & level above average \\
\hline 46.6 & high security \\
\hline
\end{tabular}

The characteristic of the relationship of resource provision with some indicators of public health. This section provides an analysis of the possible relationship of a number of indicators characterizing public health with the resource supply of districts / uluses, according to correlation coefficients calculated for the period 2007-2016. The following population health indicators were analyzed:

1) medical and demographic - birth rate, mortality, natural population growth (NPG), infant mortality (InM);
2) incidence - general and primary (of the entire population, as well as adult and child);

3) primary disability (adult and child).

In this case, only those indicators were evaluated whose dynamics was distinct either upward or downward. The correlation coefficients $r$ was taken into account with an average (0.30-0.69) and strong (0.70 and higher) degree of connection.

Verkhnevilyuysky district. The dynamics of the growth in the availability of doctors and health care facilities is combined with a decrease in MLC, while the correlation is average. In addition, the improvement in the provision of OCI is associated with a decrease in the overall incidence in children, and the deterioration in the provision with round-the-clock hospital beds is associated with an increase in child disability. And here there is an average correlation.

Vilyuisky district. Over the period under review, the availability of doctors decreased from 37.9 per 10,000 population (2007) to 30.0 (2016), while the provision of construction and medical assistance decreased from 134.9 to 108.8 , respectively. It seems quite logical that indicators of all types of morbidity and 
disability are growing. At the same time, a strong correlation is detected in the pairs of the provision of nursing staff and all types of morbidity $(r=-0.81-0.94)$, as well as the provision of doctors and disability in adults $(\mathrm{r}=-0.80)$. A less distinct relationship is found between the deterioration in the availability of roundthe-clock hospital beds and an increase in the incidence of disease. But the improvement in the availability of OCI is associated with an improvement in the medical and demographic situation (for example, in terms of total mortality $\mathrm{r}=-0.70)$.

Lensky district. It is in this area that the clearest connection is observed between the deterioration of resource endowment indicators and the increase in the incidence and disability of the population. At the same time, a strong connection is observed in the provision of round-the-clock hospital beds. For example, with the general and primary incidence of the entire population $(\mathrm{r}=-0.73)$ and with disabilities among adults and children ( $\mathrm{r}=-0.77$ and -0.80 , respectively).

Mirninsky district. In contrast to the Lensky district, in Mirninsky there is an increase in the indicators of resource provision during 2007-2016. Meanwhile, during this period there has been an improvement in the medical and demographic situation in the region, with the exception of InM. There is a particularly strong correlation with the availability of medical personnel (with a total mortality rate of $r=-0.79$, with a birth rate and NPG of $r=0.70$ and 0.85 , respectively).

Nyurbinsky district. Over the period under review, the indicators of the availability of doctors and nursing staff did not have any dynamics, remaining approximately at the same level with minor changes in one direction or another. But according to the provision of construction and medical assistance and round-theclock hospital beds, there is a dynamics of deterioration of these indicators. And at the same time, some correlation with a number of indicators of morbidity and disability can be noted.

Olekminsky district. Conclusions on this district can be made the same as on the Nyurba district. The only difference is that there is a positive trend in the availability of OCI, but there is no pronounced correlation with public health indicators.

Suntarsky district. For 2007-2016 there is a positive dynamics in the provision of doctors and OCI, and vice versa, a negative dynamics in the provision of nursing staff and round-the-clock hospital beds. It turns out that the positive dynamics in the provision of doctors and nursing staff correlates with an improvement in the medical and demographic situation, and the negative dynamics in the provision of nursing staff and around-the-clock hospital beds correlates with an increase in a number of indicators of morbidity and disability. True, $r$ indicators of an average degree of connection prevail.

\section{CONCLUSION}

Thus, it becomes obvious that in a number of WEZ uluses, the situation with the provision of medical personnel, round-the-clock hospital beds and the general medical care is generally unfavorable, with the exception of the provision of hospital beds in the Verkhnevilyuysky district in recent years.

In almost all uluses, there is a clear connection between a decrease in the level of resource provision with an increase in the general morbidity of the population. In some uluses there are correlation links with medical and demographic indicators. Another example: the increase in the availability of medical personnel, round-the-clock hospital beds and OCI in the Mirny district is combined with an improvement in the medical and demographic situation.

Earlier, we analyzed the morbidity and medical and demographic situation in the Western Economic Zone $[6,7]$. It was noted that of all the uluses/districts included in the Western Economic Zone, a favorable situation for general and primary morbidity, including depending on age groups, was detected only in Verkhneviluysky ulus. Mainly due to the low birth rate, a relatively low level of natural growth is observed in the Olekminsky and Lensky districts. Infant mortality is relatively high in the same Olekminsky, as well as in Suntarsky ulus. Mirninsky and Lensky districts differ in marriages and divorces: with high marriage rates in these areas, the level of divorce is also high.

We conclude that the planned "optimization of health care" in the form of a reduction in the number of medical personnel, hospital beds and OCI, without taking into account the dynamics of indicators characterizing the health of the population, can lead to a deterioration in public health indicators.

\section{ACKNOWLEDGMENTS}

The work was prepared based on the results of the project "Assessment, main trends in the natural and socio-economic status, human potential of the Central Economic Zone of the Republic of Sakha (Yakutia)" A comprehensive research program in the Republic of Sakha (Yakutia) aimed at developing its productive forces and social sphere in 2016-2020 years.

\section{REFERENCES}

[1] Decree of the Government of the Republic of Sakha (Yakutia) "On the draft Strategy for the socio-economic development of the Republic of Sakha (Yakutia) for the period until 2030 with the 
definition of the target vision until 2050" dated December 26, 2016, no. 455, 2016.

[2] Law of the Republic of Sakha (Yakutia) "On the Strategy for the Socio-Economic Development of the Republic of Sakha (Yakutia) until 2032 with a Targeted Vision until 2050" dated December 19, 2018, no. 2077-3, no. 45-VI, 2018.

[3] Market reviews of the main performance indicators of medical institutions of the Republic of Sakha (Yakutia) (2007-2016): stat. Sat YRMIAC of the Ministry of Health RS (Y).

[4] Statistical yearbooks of the FSGS TO in the Republic of Sakha (Yakutia) for 2000 and 2006 (2000, 2006).
[5] Statistical collections of the Yakut Republican Medical Information and Analytical Center of the Ministry of Health of the Republic of Sakha (Yakutia) (1991-2017).

[6] L.F. Timofeev, P.G. Petrova, N.V. Borisova et al., Morbidity of the population in the Western economic zone of the Republic of Sakha (Yakutia), Bull. of the NEFU M. K. Ammosov 3(12) (2018) 77-81.

[7] L.F. Timofeev, P.G. Petrova, N.V. Borisova et al., The medical and demographic situation in the Western economic zone of the Republic of Sakha (Yakutia), Bull. of the NEFU M. K. Ammosov 4(13)

(2018) 91-102. 